\title{
Brønsted Acid Catalyzed Tandem Defunctionalization of Biorenewable Ferulic acid and Derivates into Bio-Catechol
}

\author{
Jeroen Bomon, Elias Van Den Broeck, Mathias Bal, Yuhe Liao, Sergey Sergeyev, \\ Veronique Van Speybroeck, Bert F. Sels, and Bert U. W. Maes*
}

\begin{abstract}
An efficient conversion of biorenewable ferulic acid into bio-catechol has been developed. The transformation comprises two consecutive defunctionalizations of the substrate, that is, $\mathrm{C}-\mathrm{O}$ (demethylation) and $\mathrm{C}-\mathrm{C}$ (de-2-carboxyvinylation) bond cleavage, occurring in one step. The process only requires heating of ferulic acid with $\mathrm{HCl}\left(\mathrm{or} \mathrm{H}_{2} \mathrm{SO}_{4}\right)$ as catalyst in pressurized hot water $\left(250^{\circ} \mathrm{C}, 50\right.$ bar $\left.\mathrm{N}_{2}\right)$. The versatility is shown on a variety of other (biorenewable) substrates yielding up to $84 \%$ di- (catechol, resorcinol, hydroquinone) and trihydroxybenzenes (pyrogallol, hydroxyquinol), in most cases just requiring simple extraction as work-up.
\end{abstract}

W the decline of petroleum feedstock and the necessity to reduce $\mathrm{CO}_{2}$ emission, society must innovate to discover new, more sustainable means to meet the needs of an ever expanding world population. ${ }^{[1]}$ The manufacture of products based upon (bio)renewable resources is one of the ways to address this. ${ }^{[2]}$ Particularly, (hemi)cellulose derived products have already been investigated intensively and found mature applications in industry. ${ }^{[3]}$ However, these bio-polymers do not contain aromatic moieties, requiring other parts of plant tissue to produce these key entities in chemical industry. BTX, obtained in oil refinery with 60 megatonsyear $^{-1}{ }^{[4]}$ is the current arene source of the chemical industry. Fractions thereof are transformed into building blocks of higher oxidation state and used in the production of a variety of plastics, rubbers, and other materials. ${ }^{[5]}$ Biorenewables offer the potential to access intermediates toward these building blocks directly in the right oxidation state as a result of high functionality.

One particularly interesting biorenewable aromatic compound is ferulic acid (1a), found in plant cell walls covalently linked to (hemi)cellulose and lignin. ${ }^{[6]}$ In most cases, it is obtained as a waste compound of the rice industry, by extraction from rice bran, ${ }^{[7]}$ and therefore readily available on a large scale. Rice bran derived $\mathbf{1 a}$ is used by Solvay to

[*] J. Bomon, M. Bal, Dr. S. Sergeyev, Prof. Dr. B. U. W. Maes Organic Synthesis, Department of Chemistry, University of Antwerp Groenenborgerlaan 171, 2020 Antwerp (Belgium)

E-mail: bert.maes@uantwerpen.be

E. Van Den Broeck, Prof. Dr. V. Van Speybroeck

Center for Molecular Modeling, Ghent University

Technologiepark 46, 9052 Zwijnaarde (Belgium)

Dr. Y. Liao, Prof. Dr. B. F. Sels

Center for Sustainable Catalysis and Engineering, KU Leuven Celestijnenlaan 200F, 3001 Leuven (Belgium) produce vanillin industrially ("Rhovanil Natural") by biocatalysis (fermentation). ${ }^{[8]}$ Interestingly, 1a contains a 4-substituted catechol moiety as core structure. Catechol (2) is a major commodity chemical (40 kilotons year ${ }^{-1}$ ) petrochemically mainly produced through hydroxylation of phenol, $\left.{ }^{[5, \mathrm{a}]}\right]$ synthesized from benzene by the cumene Hock process. $\mathbf{2}$ is used in a wide range of applications (anticorrosion agent, antioxidant, chelating agent, detergent) and as a raw material for pharmaceuticals, pesticides, flavors, fragrances, and polymer synthesis. ${ }^{[5]}$ "Unlocking" the catechol core from 1 a may be a great opportunity but challenging, given a sequence of two defunctionalization steps, that is, $O$ - and $C$-dealkylation, is required. Metabolic pathways in fermentative processes involving such cascade have been described, but complex reaction mixtures were obtained resulting in a difficult isolation of 2, with a yield less than $9 \%$ and low titer (Scheme 1a) ${ }^{[9]}$ Bio-catechol manufacturing using such a biological approach may therefore not be favorable from a synthetic point of view.

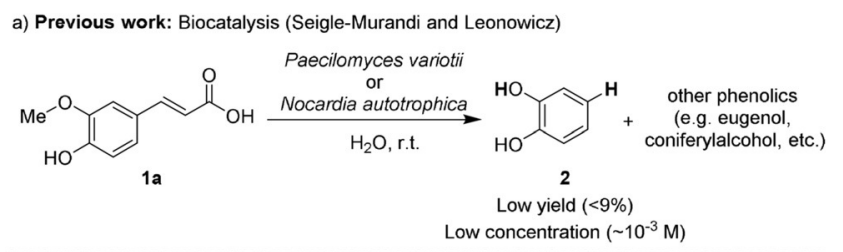

b) This work: Chemocatalysis

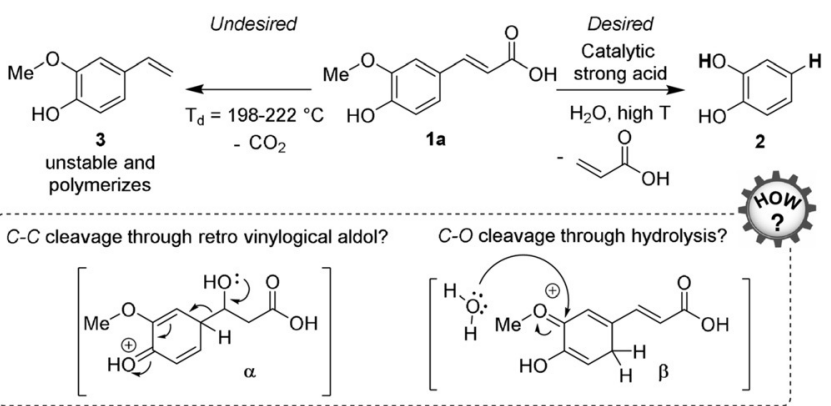

Scheme 1. Transformation of ferulic acid into bio-catechol and proposed key intermediates for $\mathrm{O}$ - and $\mathrm{C}$-dealkylation.

Given the industrial importance of catechol and absence of a one step process utilizing a biorenewable feedstock, a high yielding chemocatalytic pathway from ferulic acid (1a) involving practical isolation would be appealing (Scheme 1b). Use of ferulic acid as a substrate in chemical transformations is a serious synthetic challenge given its thermal instabilityneat or in water-causing decarboxylation to 4-vinylguaiacol 
(3) ${ }^{[10]}$ an unstable and easily polymerizable styrene derivative. ${ }^{[11]}$ Studies on dealkylation of guaiacol derivatives are scarce since only two reports described the deallylation of eugenol into guaiacol, but unfortunately low yield (about $10 \%)$ and selectivity were obtained. ${ }^{[12]}$ Application of these protocols on ferulic acid provided guaiacol below $5 \%$ yield (See Supporting Information, Section 3). Therefore, another synthetic approach to efficiently transform $\mathbf{1 a}$ into catechol (2) has to be searched for. We reasoned that addition of water into the $\alpha, \beta$-unsaturated acid moiety and protonation of the electron-rich arene unit of ferulic acid (1a) delivers an intermediate $\boldsymbol{\alpha}$ (Scheme $1 \mathrm{~b}$ ), potentially allowing $\mathrm{C}-\mathrm{C}$ bond cleavage through a retro vinylogical aldol reaction. To the best of our knowledge, such dealkylation reaction is unprecedented. In $O$-demethylation of guaiacols, protonation of the electron-rich arene is supposed to, again, play a key role (intermediate $\boldsymbol{\beta}$, Scheme $1 \mathrm{~b}$ ). The published $O$-demethylations of guaiacol (18) with aqueous strong acids support feasibility ${ }^{[13,14]}$ Interestingly, the proposed mechanism in our hypothesis suggests $O$ - rather than arene protonation as activation mode. ${ }^{[13]}$ The Michael addition, $C$-dealkylation and $O$-demethylation theoretically all require only protons to act as electrophile and water as reactant and can therefore occur in a tandem fashion. These aspects make this novel route attractive from a green chemistry point of view.

Preliminary experiments revealed that heating ferulic acid (1a) in water at $250{ }^{\circ} \mathrm{C}$ for $3 \mathrm{~h}$ with an initial back pressure of 50 bar $\mathrm{N}_{2}$ led to complete decomposition (Table 1, Entry 1), in line with its known thermal instability at atmospheric pressure. ${ }^{[10]}$ This was also the case with addition of $20 \mathrm{~mol} \%$

Table 1: Selected optimization data of the acid catalyzed tandem $O$ - and C-dealkylation of ferulic acid (1 a) into catechol (2).<smiles>COc1cc(/C=C/C(=O)O)ccc1O</smiles>
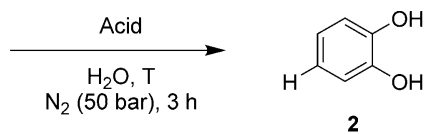

\begin{tabular}{|c|c|c|c|c|c|}
\hline Entry & Conc. [M] & $\begin{array}{l}\text { Acid } \\
\text { (mol\%) }\end{array}$ & $\mathrm{p} K_{\mathrm{a}}$ & $T\left[{ }^{\circ} \mathrm{C}\right]$ & $2^{[a]}[\%]$ \\
\hline 1 & 0.50 & - & - & 250 & 0 \\
\hline 2 & 0.50 & HOAc (20) & 4.8 & 250 & 0 \\
\hline 3 & 0.50 & $\mathrm{H}_{3} \mathrm{PO}_{4}(20)$ & 2.2 & 250 & 19 \\
\hline 4 & 0.50 & $\mathrm{H}_{2} \mathrm{SO}_{4}(20)$ & -3.0 & 250 & 38 \\
\hline 5 & 0.50 & $\mathrm{HCl}(20)$ & -7.0 & 250 & 42 \\
\hline 6 & 0.50 & HOTf (20) & -15 & 250 & 35 \\
\hline 7 & 0.13 & $\mathrm{HCl}(50)$ & -7.0 & 250 & $69\left(70^{[b]}\right)$ \\
\hline 8 & 1.00 & $\mathrm{HCl}(50)$ & -7.0 & 250 & $27\left(27^{[b]}\right)$ \\
\hline 9 & 0.13 & $\mathrm{HCl}(50)$ & -7.0 & 230 & $25\left(36^{[b]}\right)$ \\
\hline 10 & 0.13 & $\mathrm{HCl}(50)$ & -7.0 & 200 & $16^{[c]}$ \\
\hline 11 & 0.13 & $\mathrm{HCl}(50)$ & -7.0 & 175 & 0 \\
\hline 12 & 0.13 & $\mathrm{HCl}(25)$ & -7.0 & 250 & $43\left(49^{[b]}\right)$ \\
\hline 13 & 0.13 & $\mathrm{HCl}(50)$ & -7.0 & 275 & $58\left(61^{\mathrm{b}]}\right)$ \\
\hline $14^{[\mathrm{d}]}$ & 0.13 & $\mathrm{HCl}(25)$ & -7.0 & 275 & $65\left(67^{[b]}\right)$ \\
\hline 15 & 0.13 & $\mathrm{H}_{2} \mathrm{SO}_{4}(50)$ & -3.0 & 250 & $41\left(44^{[b]}\right)$ \\
\hline 16 & 0.13 & $\mathrm{H}_{2} \mathrm{SO}_{4}(100)$ & -3.0 & 250 & $49\left(55^{[b]}\right)$ \\
\hline
\end{tabular}

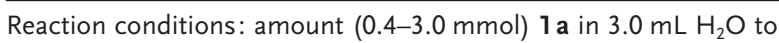
achieve the given concentration. [a] ${ }^{1} \mathrm{H}$ NMR yield determined with dimethyl sulfone as int. std. For all entries, full conversion of 1 a was observed. [b] Yield of isolated product. [c] Next to 2, 18 was obtained in $27 \%$ yield. [d] Reaction time: $2 \mathrm{~h}$.
HOAc (Entry 2). Interestingly, catechol (2) formation was observed (Entries 3-6) when increasing the acid strength $\left(\mathrm{H}_{3} \mathrm{PO}_{4}, \mathrm{H}_{2} \mathrm{SO}_{4}, \mathrm{HCl}\right.$, HOTf). Unfortunately, a low yield (19$42 \%)$ and moderate selectivity were observed in all those cases. $\mathrm{HCl}$ was chosen for further optimization, given its abundance and low cost. Moreover, it is recommended based on a green acid selection guide. ${ }^{[15]}$ Optimization revealed the yield of $\mathbf{2}$ was increased by decreasing the concentration of $\mathbf{1 a}$ (Entries 7,8) and increasing $\mathrm{HCl}$ loading (Entries 7, 12), with, respectively $0.13 \mathrm{M}$ and $50 \mathrm{~mol} \%$ as optimal parameters. This way, $\mathbf{2}$ was isolated in $70 \%$ yield (Entry 7 ). Importantly, a high temperature is crucial for selectivity. Decreasing the temperature led to full decomposition of the substrate (Entries 7, 911 ), whereas increasing the temperature (for example to $275^{\circ} \mathrm{C}$ ) essentially gave the same yield after $2 \mathrm{~h}$, even with half of the amount of acid (Entries 7, 13, 14). For $\mathrm{H}_{2} \mathrm{SO}_{4}$, the highest yield of $\mathbf{2}$ (55\%) was observed when using a stoichiometric amount of acid (Entries 15, 16). The type of acid and amount are crucial to suppress undesired polymerizations, which could be confirmed by LC-MS. Full optimization can be found in the Supporting Information (Section 4).

The optimal reaction conditions were applied on ferulic acid derivatives (Scheme 2). Caffeic acid (1) $)$, isoferulic acid (1c), and 3,4-dimethoxycinnamic acid (1d) gave catechol (2) in a similar yield. Dimethoxycinnamic acid isomers 1e-h delivered the expected dihydroxybenzene, that is, $\mathbf{2}$, resorcinol (4) or hydroquinone (5), in 57-84\% yield. No intermediates involving only $O$ - or $C$-dealkylation were observed. Remarkably, using 3,5-dimethoxycinnamic acid (1i) as substrate did not deliver resorcinol, which was also the case for 3,5-dihydroxycinnamic acid (1j). Interestingly, when a hydroxy group was introduced at the 4-position of 3,5-dimethoxycinnamic acid (1k), pyrogallol (6) was formed in 59\% yield. These results show that an ortho or para relation between one of the methoxy or hydroxy groups and the propenoic acid moiety is crucial to allow $C$-dealkylation.

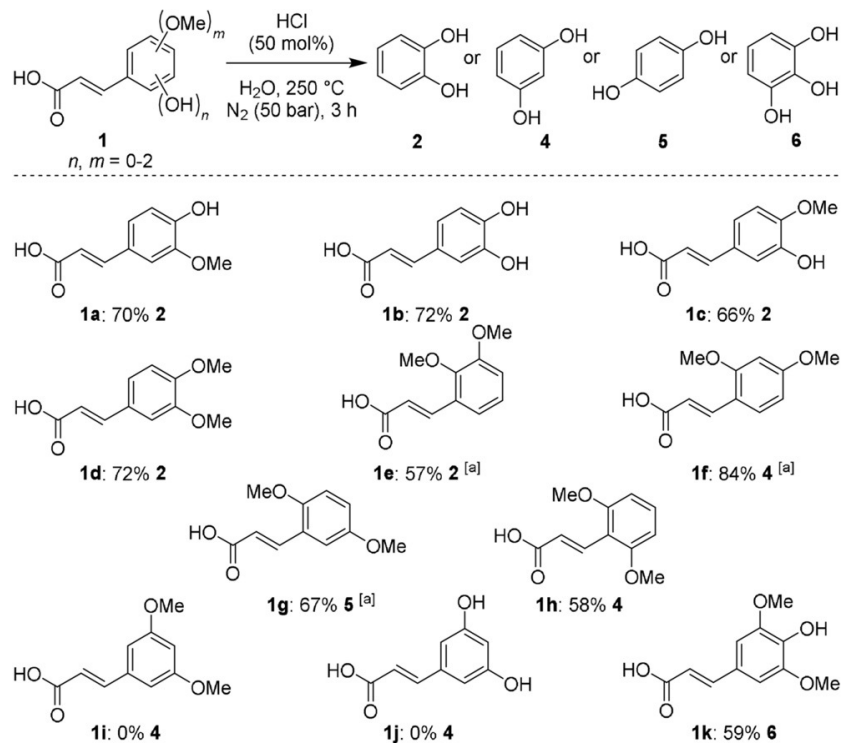

Scheme 2. $\mathrm{O}$ - and C-dealkylation of hydroxylated and/or methoxylated cinnamic acid regioisomers. Yields of isolated products. ${ }^{[a]}$ Reaction time $=4.5 \mathrm{~h}$. 
Next, we examined whether other guaiacol derivatives featuring different carbon chains than a propenoic acid on the aromatic ring can be cleaved off (Scheme 3). Esters of ferulic acid reduced the yield of catechol (2) with increasing chain length (methyl (8a), ethyl (8b), and propyl (8c) ester), linked to substrate solubility. Chlorogenic acid (9), involved in

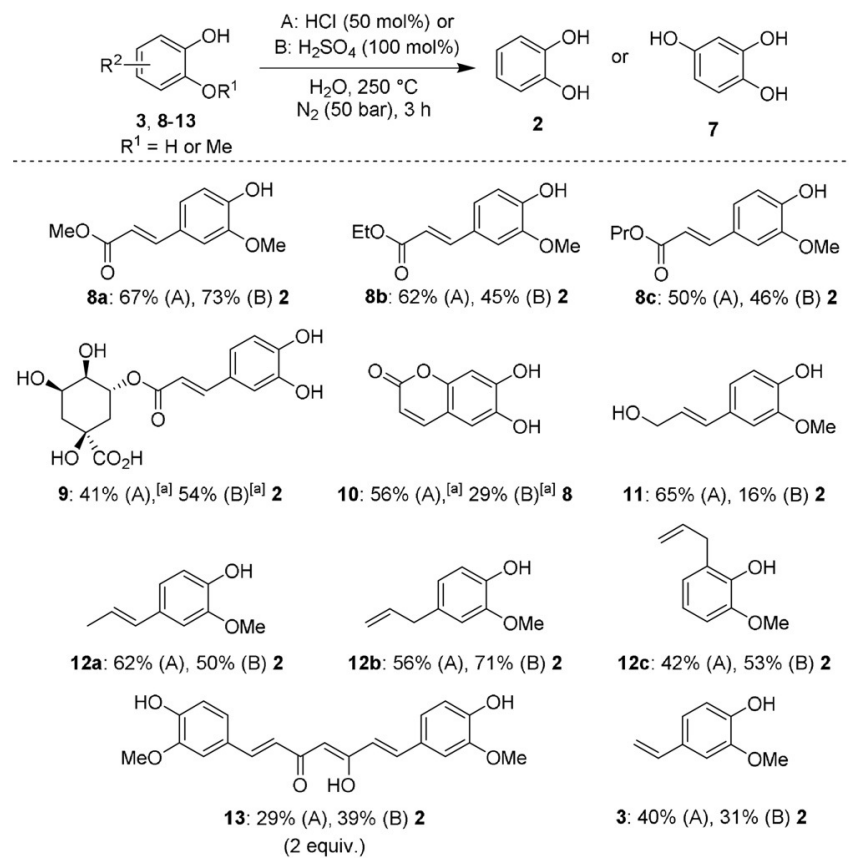

Scheme 3. O- and C-dealkylation of C-substituted catechol and guaiacol derived substrates. Yields of isolated products. ${ }^{[a]}$ Column chromatography.

biosynthesis of lignin, ${ }^{[16]}$ delivered 2 in $41 \%$ yield. Lacton esculetin (10), the main active ingredient of the traditional Chinese medicine Cortex Fraxini, ${ }^{[17]}$ gave hydroxyquinol (7) with a yield of $56 \%$. Other propenyl containing substrates, that is, coniferylalcohol (11), isoeugenol (12a), eugenol (12 b), and ortho-eugenol (12 c), also cleaved with the formation of 2 in yields ranging from 42 to $65 \%$. Curcumin (13) is a registered food additive (E100) made up of two ferulic acid molecules in its biosynthesis. ${ }^{[18]}$ It contains an $\alpha, \beta$ - and an $\alpha, \beta, \gamma, \delta$-unsaturated carbonyl chain, each connected to a guaiacol unit. Interestingly, our standard conditions also allowed $\mathrm{C}-\mathrm{C}$ bond cleavage affording 2. 4-Vinylguaiacol (3), the known product for thermal decomposition of $\mathbf{1} \mathbf{a}^{[10 \mathrm{a}]}$ was also cleaved into $\mathbf{2}$. Therefore, transformation of $\mathbf{1 a}$ in $\mathbf{2}$ via $\mathbf{3}$ is also a possible reaction pathway. However, the significant difference in yield of $\mathbf{2}$ starting from $\mathbf{1 a}(70 \%)$ and $\mathbf{3}(40 \%)$ indicate that this cannot be the only pathway. Moreover, when the reaction was performed under 50 bar of a mixture of $\mathrm{CO}_{2}: \mathrm{N}_{2}(60: 40)$ rather than $\mathrm{N}_{2}$, a similar yield of $2(72 \%)$ was observed further supporting that decarboxylation is not an important process under our conditions. This points to addition of water into the $\alpha, \beta$-unsaturated acid moiety forming intermediate $\boldsymbol{\alpha}$ (Scheme $1 \mathrm{~b}$ ) hereby protecting it from decarboxylation into $\mathbf{3}$. It is worth mentioning that for all these substrates in Scheme 3 the optimized reaction conditions for the defunctionalization of ferulic acid were applied (Table 1, Entry 7) without any further optimization. Fine tuning of the reaction conditions for individual compounds will further improve the yields. This is exemplified by applying alternative conditions, involving $100 \mathrm{~mol} \% \mathrm{H}_{2} \mathrm{SO}_{4}$ (Table 1, Entry 15) which sometimes gave a higher yield (8a, $\mathbf{9}, \mathbf{1 2 b}, \mathbf{1 2} \mathrm{c}, \mathbf{1 3}$ ) (Scheme 3). For all substrates, except 9 and $\mathbf{1 0}$, simple work-up with extraction (no column chromatography) suffice, beneficial for the green credentials of the methodology. ${ }^{[19]}$ Considering temperature was crucial in the transformation of $\mathbf{1} \mathbf{a}$ into $\mathbf{2}$, we have selected four other substrates $(\mathbf{3}, \mathbf{1 2} \mathbf{a}, \mathbf{1 2} \mathbf{b}$, and $\mathbf{1 3})$ to evaluate this effect. At $150^{\circ} \mathrm{C}$, under otherwise optimal reaction conditions, full decomposition of the substrate was observed in all cases, as noted for $\mathbf{1 a}$ (Table 1, Entry 11). No catechol (2) could be detected in the crude reaction mixtures.

4-Propylguaiacol (14) produced 4-propylcatechol (16) in $97 \%$, while unsaturated derivatives eugenol (12b) and isoeugenol (12a) exclusively gave catechol (2) (Scheme 4). Dihydroferulic acid (15), featuring a propanoic acid, transformed into dihydrocaffeic acid (17) in $82 \%$ yield without showing any $C$-defunctionalization, while unsaturated derivative ferulic acid (1a) exclusively gave $\mathbf{2}$ under the same conditions. Unsaturation in the side chain is thus primordial for the $C$-dealkylation. ${ }^{[20,21]}$

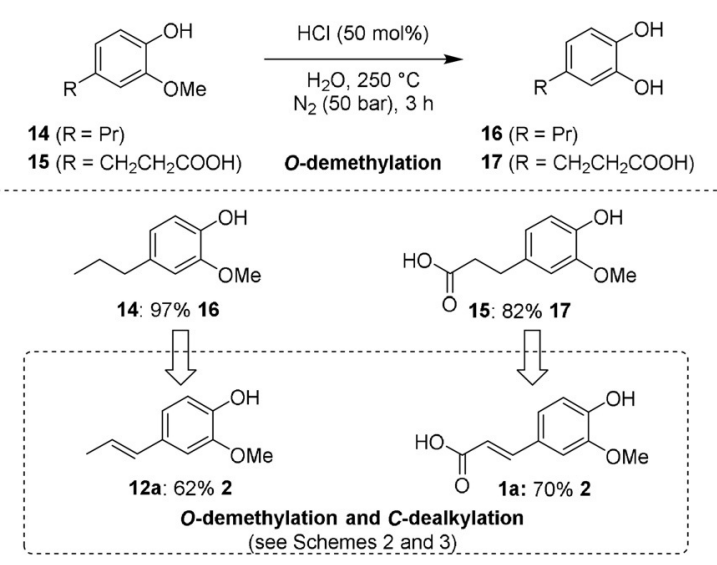

Scheme 4. O-demethylation of C-substituted guaiacol derivatives.

The proposed mechanism of the $O$ - and $C$-dealkylation reaction of guaiacol derivatives is exemplified on ferulic acid (1a), isoeugenol (12a), and eugenol (12b) (Scheme 5). Treatment of the substrate with acid in water leads to the formation of a benzylic alcohol A through addition of water to the alkene. The phenolic hydroxy group directs protonation on the carbon atom ipso to the alkyl chain. The obtained intermediate $\mathbf{B}$ then allows $\mathrm{C}-\mathrm{C}$ bond cleavage through a retro vinylogical aldol reaction, delivering guaiacol (18) and aldehyde 19 or 20. First principle static and dynamic molecular simulations support the proposed $C$-dealkylation (See Supporting Information, Section 7). These calculations also revealed that this cleavage reaction is in competition with proton transfer of unstable intermediate $\mathbf{B}$ to the solvent, yielding $\mathbf{C}$, which can reprotonate. The $O$-demethylation reaction of $\mathbf{1 8}$ is initiated by protonation of the arene into $\mathbf{D}$. 

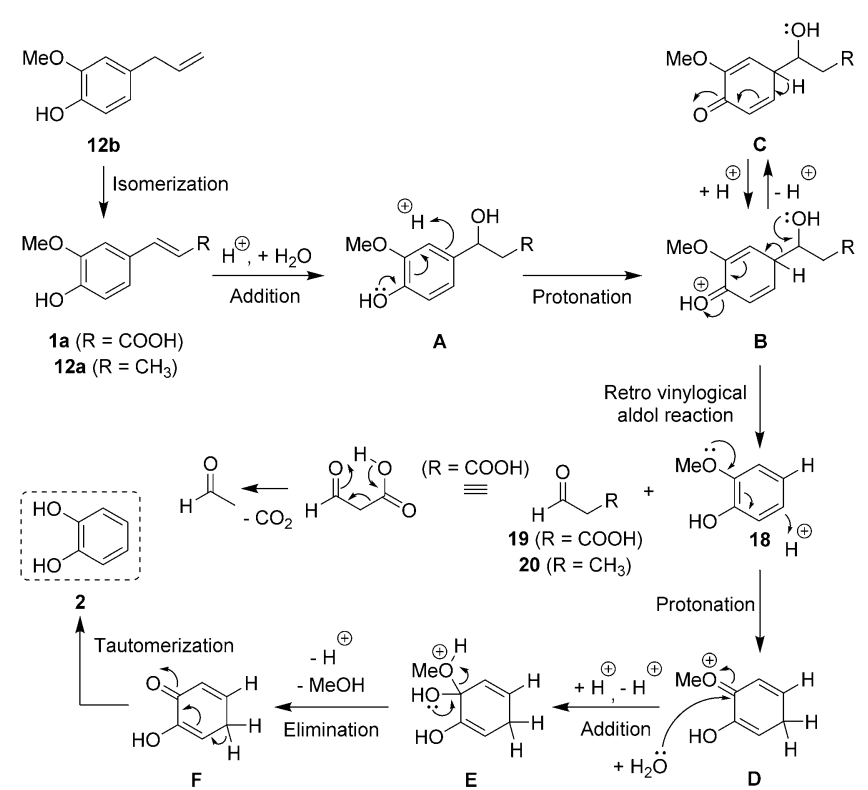

A
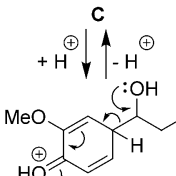

B
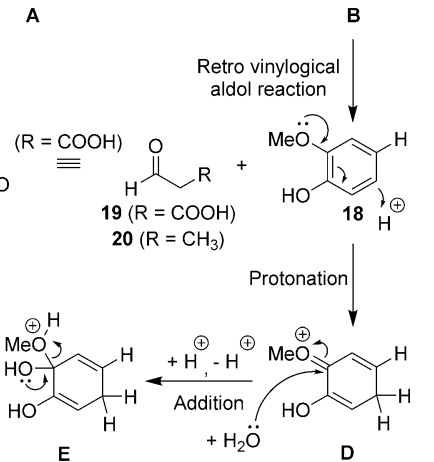

Scheme 5. Proposed mechanism for the $O$ - and C-dealkylation of ferulic acid (1 a), isoeugenol (12a), and eugenol (12b) into catechol (2).

Subsequent addition of water gives hemiacetal $\mathbf{E}$, which upon elimination of methanol provides 6-hydroxycylohexa-2,4dien-1-one $(\mathbf{F})$, in which aromaticity is restored through tautomerization to deliver $\mathbf{2}$. Intermediates $\mathbf{D}, \mathbf{E}$, and $\mathbf{F}$ were confirmed by theoretical calculations (See Supporting Information, Section 7). These also indicated $O$-demethylation via $\mathrm{S}_{\mathrm{N}} 2$ of water on $\mathbf{D}$ is not favored. However, accounting for the environment and operating conditions more accurately, by means of advanced molecular dynamics simulations, will further elucidate the nature of the $O$-demethylation mechanism. Demethylation initiated via $C$-arene rather than $O$ protonation is uncommon. ${ }^{[13]} O$ - and $C$-dealkylations may also occur in the reverse order.

Model substrates were selected to further support the mechanism experimentally (Scheme 6). This study was performed with different veratrole rather than with guaiacol derivatives. 3,4-Dimethoxycinnamic acid (1d) transformed into catechol $(\mathbf{2}, 72 \%)$ (Scheme 6A). Gratifyingly, methanol $(87 \%)$ was also observed in the crude reaction mixture before extraction. Benzylic alcohol 21, also allowed cleavage into the same reaction products, supporting its potential role as intermediate formed by addition of water on the alkene moiety of $\mathbf{1 d}(6 \mathrm{~B})$. However, it still remains unclear whether 21 is an intermediate in the $C$-dealkylation reaction mechanism as it can eliminate water into $\mathbf{1 d}$. Therefore $\mathbf{2 2}$ was selected, featuring geminal methyl groups at the $\beta$-carbon atom, blocking elimination (6C). This compound also cleaved into catechol and methanol, showing that the benzylic alcohol and not the alkene is indeed crucial in $\mathrm{C}-\mathrm{C}$ cleavage. In none of the reactions $6 \mathrm{~A}-\mathrm{C}$, the proposed aldehyde by-product 19 or 23 was observed in the crude reaction mixture. $\beta$ Oxopropenoic acids undergo decarboxylation at elevated temperature, leading to the formation of acetaldehyde and isobutyraldehyde which are volatile compounds, furthermore

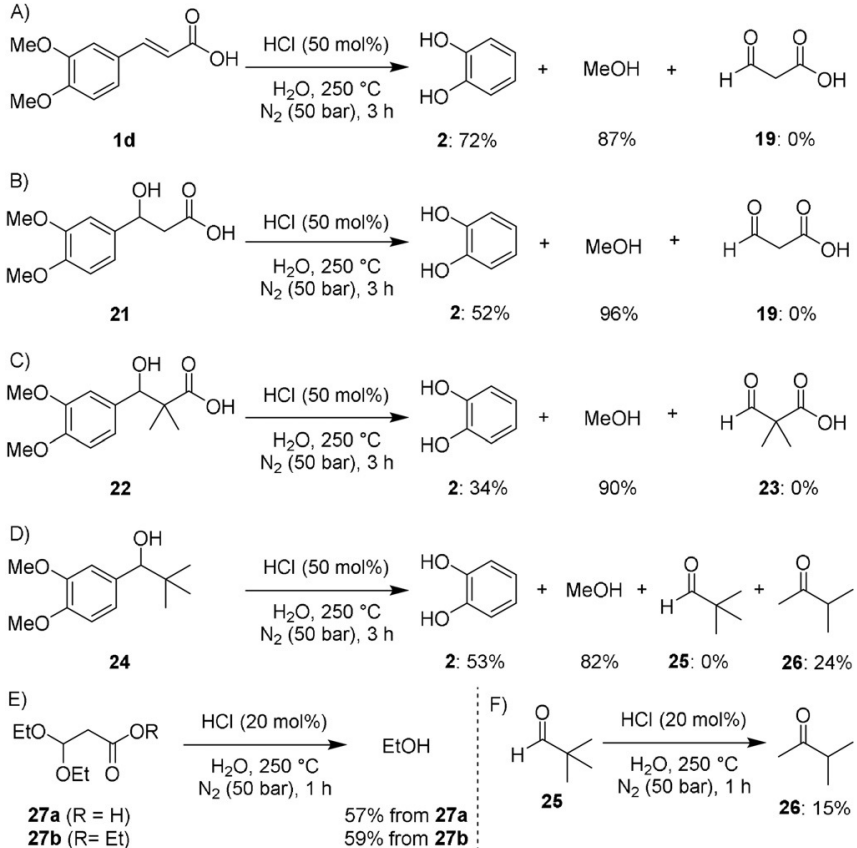

$27 \mathrm{~b}(\mathrm{R}=\mathrm{E})$

Scheme 6. Supporting experiments for the mechanism in Scheme 5. ${ }^{1} \mathrm{H}$ NMR yields of the crude reaction mixture, measured with suppression of the water signal and with dimethylsulfone as internal standard.

prone to polymerization. ${ }^{[22]}$ This is supported with the complete decomposition of acetals 27 under the reaction conditions $(6 \mathrm{E})$, yielding ethanol as the only observable product. To prove the involvement of an aldehyde, another substrate was designed in which the carboxylic acid function was replaced by a methyl group (6D). Gratifyingly, 24 delivered catechol (2), methanol and methyl isopropyl ketone (26) as reaction products. $\mathbf{2 6}$ is a rearrangement product of pivaldehyde (25), which was confirmed in an independent reaction $(6 \mathrm{~F}) .^{[23]}$

Realizing that a benzylic alcohol is primordial in the $\mathrm{C}-\mathrm{C}$ bond cleavage process, we looked into the behavior of lignin model compound $\mathbf{2 8} \mathbf{a},{ }^{[24]}$ which contains the most abundant $\beta$ $O-4$ bond of lignin (Scheme 7). ${ }^{[2]}$ Under the standard conditions, $33 \%$ catechol (2) could be detected which increased to $53 \%$ when halving the $\mathrm{HCl}$ loading. Interestingly, methanol was obtained as by-product from $O$-demethylation. Model compound $\mathbf{2 8} \mathbf{b}$, containing a guaiacol and a syringol unit cleaved into 2 (28\%) and pyrogallol (6) (36\%). Literature reports on $\beta-O-4$ model compound cleavage with mineral acids leads to $C$-substituted guaiacol and syringol derivatives, without removing the whole carbon chain. ${ }^{[25]}$ These proceed via a benzylic cation 29 at $\alpha$, inducing cleavage into $\mathrm{C} 2$ and $\mathrm{C} 3$ fragments. Use of $\mathrm{H}_{2} \mathrm{SO}_{4}$ in water at $150^{\circ} \mathrm{C}$ on 28a for example yielded $23 \% \mathbf{1 8}, 12 \%$ ketone $\mathbf{3 0}$, and $3 \%$ aldehyde 31, ${ }^{[23 \mathrm{~b}]}$ while under our conditions at $250{ }^{\circ} \mathrm{C} 25 \% \mathbf{2}$ and $69 \%$ methanol were formed. This remarkable difference observed is due to the protonation of the arene ring, allowing an alternative cleavage from $\mathbf{2 8}$. Similarly, $O$-demethylation is induced by arene protonation, rationalizing why it is not observed in the literature procedures on lignin model compounds. ${ }^{[25]}$ Hot pressurized water is known for its special 


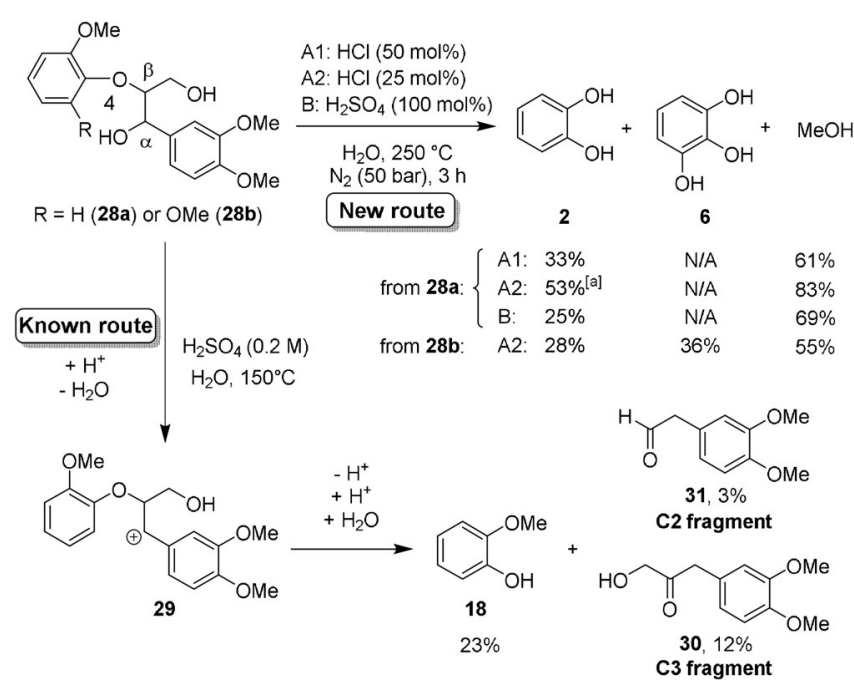

Scheme 7. O- and C-dealkylation of $\beta$-O-4 lignin model compounds 28 with mineral acids. ${ }^{1} \mathrm{H}$ NMR yields with dimethyl sulfone as int. std. ${ }^{[a]}$ Yield of the isolated product: $42 \%$.

features, including increased acidity, presumably responsible to access $\mathbf{B}$ and $\mathbf{D}$. $^{[26]}$

In conclusion, we have developed a novel tandem reaction for the $O$ - and $C$-defunctionalization of ferulic acid into biocatechol catalyzed by Brønsted acids in hot pressurized water. The versatility of the method is demonstrated by accessing various dihydroxy- and trihydroxybenzenes from other (natural) substrates, in most cases only requiring simple extraction of the reaction mixture as work-up. A benzylic alcohol (intermediate) proved to be crucial in the $C$-dealkylation reaction. The by-product of $C$-dealkylation is the corresponding aldehyde, while for $O$-demethylation it is methanol. Considering the defunctionalization process involves several reactions, the yields obtained are good. When applying this method on lignin model compounds, featuring the most abundant $\beta-O-4$ bond of lignin, catechol and pyrogallol were also formed.

\section{Acknowledgements}

The authors acknowledge financial support from the Research Foundation Flanders (FWO) (WOG and BioFact Excellence of Science project Grant No. 30902231), UAntwerp (BOF), Research Board of UGent, VLAIO/Catalisti (ARBOREF), the BIO-HarT project (established by a contribution of the European Interreg V Flanders-The Netherlands program that stimulates innovation, sustainable energy, a healthy environment, and the labor market by means of cross-border projects), the Hercules and Francqui Foundation. We thank Dr. M. Smoleń, S. Adriaensen, G. Mollaert, P. Franck, and Prof. F. Lemière for their contribution and Dr. J. Snaet for the design of the cover illustration. The computational resources and services used were provided by UGent (Stevin Supercomputer Infrastructure) and the VSC (Flemish Supercomputer Center) funded by FWO.

\section{Conflict of interest}

The authors declare no conflict of interest.

Keywords: green chemistry - O-dealkylation - C-dealkylation . renewable resources bond cleavage

[1] a) BP p.l.c., "BP Statistical Review of World Energy, 67th edition”, 2018; b) J. Tollefson, Nature 2018, 10.1038/d41586-01807566-07569.

[2] R. Rinaldi, R. Jastrzebski, M. T. Clough, J. Ralph, M. Kennema, P. C. Bruijnincx, B. M. Weckhuysen, Angew. Chem. Int. Ed. 2016, 55, 8164; Angew. Chem. 2016, 128, 8296.

[3] a) A. Shrotri, H. Kobayashi, A. Fukuoka, Acc. Chem. Res. 2018, 51, 761; b) J. S. Luterbacher, D. Martin Alonso, J. A. Dumesic, Green Chem. 2014, 16, 4816; c) S. Van de Vyver, J. Geboers, P. A. Jacobs, B. F. Sels, Chem CatChem 2011, 3, 82

[4] "BTX Processing": W. A. Sweeney, P. F. Bryan, Kirk-Othmer Encyclopedia of Chemical Technology, Wiley, Hoboken, 2008.

[5] a) GEP, Catechol Faces Supply Crunch While Prices Rise 2018 https://www.gep.com/mind/blog/catechol-faces-supply-crunchwhile-prices-rise; b) "Phenol": M. Weber, M. Weber, M. KleineBoymann, Ullmann's Encyclopedia of Industrial Chemistry, Wiley-VCH, Weinheim, 2004; c) "Benzene": H. O. Folkins, Ullmann's Encyclopedia of Industrial Chemistry, Wiley-VCH, Weinheim, 2000; d) "Phenol Derivatives": H. Fiege, H.-W. Voges, T. Hamamoto, S. Umemura, T. Iwata, H. Miki, Y. Fujita, H.-J. Buysch, D. Garbe, W. Paulus, Ullmann's Encyclopedia of Industrial Chemistry, Wiley-VCH, Weinheim, 2000.

[6] N. Gopalan, L. V. Rodriguez-Duran, G. Saucedo-Castaneda, K. M. Nampoothiri, Bioresour. Technol. 2015, 193, 534.

[7] H. T. Truong, M. D. Van, L. D. Huynh, L. T. Nguyen, A. D. Tuan, T. L. X. Thanh, H. D. Phuoc, N. Takenaka, K. Imamura, Y. Maeda, Appl. Sci. 2017, 7, 796.

[8] a) M. M. Bomgardner, Chem. Eng. News 2013, 49, 18; b) H. Priefert, J. Rabenhorst, A. Steinbuchel, Appl. Microbiol. Biotechnol. 2001, 56, 296.

[9] a) E. Malarczyk, J. Rogalski, A. Leonowicz, Acta Biotechnol. 1994, 14, 235; b) M. Rahouti, F. Seigle-Murandi, R. Steiman, K. E. Eriksson, Appl. Environ. Microbiol. 1989, 55, 2391.

[10] a) Y. Cheng, Q. Z. Xu, J. Liu, C. S. Zhao, F. M. Xue, Y. Z. Zhao, J. Braz. Chem. Soc. 2014, 25, 2102; b) W. Fiddler, W. E. Parker, A. E. Wasserman, R. C. Doerr, J. Agric. Food Chem. 1967, 15, 757.

[11] H. Takeshima, K. Satoh, M. Kamigaito, Macromolecules 2017, 50, 4206.

[12] a) T. Nimmanwudipong, R. C. Runnebaum, S. E. Ebeler, D. E. Block, B. C. Gates, Catal. Lett. 2012, 142, 151; b) J. B. Binder, M. J. Gray, J. F. White, Z. C. Zhang, J. E. Holladay, Biomass Bioenergy 2009, 33, 1122 .

[13] For $O$-demethylation of guaiacol derivatives with strong acids, see: a) aq. HBr: E. Blondiaux, J. Bomon, M. Smoleń, N. Kaval, F. Lemière, S. Sergeyev, L. Diels, B. Sels, B. U. W. Maes, ACS Sustainable Chem. Eng. 2019, 7, 6906; b) aq. HBr: S. Zhao, M. M. Abu-Omar, Biomacromolecules 2015, 16, 2025; c) aq. $\mathrm{HCl}$ and $\mathrm{H}_{2}$ : L. Yang, W. Zhou, K. Seshan, Y. D. Li, J. Mol. Catal. A 2013, 368, 61 .

[14] For other $O$-demethylations of guaiacol derivatives, see: a) Biocatalytic: E. Lanfranchi, M. Trajkovic, K. Barta, J. G. de Vries, D. B. Janssen, ChemBioChem 2019, 20,118; b) Biocatalytic: J. E. Farnberger, N. Richter, K. Hiebler, S. Bierbaumer, M. Pickl, W. Skibar, F. Zepeck, W. Kroutil, Commun. Chem. 2018, 1, 82; c) Al and $\mathrm{I}_{2}$ : J. Tian, H. Yue, P. Yang, D. Sang, ChemistrySelect 2019, 4, 
38; d) $\mathrm{AlI}_{3}$ and DMSO: J. Tian, D. Sang, X. Tu, Z. He, M. Yao, Synthesis 2018, 51, 704; e) $\mathrm{AlCl}_{3}$ and NaI: D. Sang, X. Tu, J. Tian, Z. He, M. Yao, ChemistrySelect 2018, 3, 10103; f) $\mathrm{BBr}_{3}$ : L. Li, D Qiu, J. Shi, Y. Li, Org. Lett. 2016, 18, 3726; g) TMSI: H. D. Basavarajappa, B. Lee, H. Lee, R. S. Sulaiman, H. An, C Magana, M. Shadmand, A. Vayl, G. Rajashekhar, E. Y. Kim, Y. G. Suh, K. Lee, S. Y. Seo, T. W. Corson, J. Med. Chem. 2015, 58, 5015; h) SIBX: A. Ozanne, L. Pouysegu, D. Depernet, B. Francois, S. Quideau, Org. Lett. 2003, 5, 2903.

[15] R. K. Henderson, A. P. Hill, A. M. Redman, H. F. Sneddon, Green Chem. 2015, 17, 945.

[16] W. Boerjan, J. Ralph, M. Baucher, Annu. Rev. Plant. Biol. 2003, $54,519$.

[17] C. Liang, W. Ju, S. Pei, Y. Tang, Y. Xiao, Molecules 2017, 22, 387.

[18] P. Oyarce, B. De Meester, F. Fonseca, L. de Vries, G. Goeminne, A. Pallidis, R. De Rycke, Y. Tsuji, Y. Li, S. Van den Bosch, B. Sels, J. Ralph, R. Vanholme, W. Boerjan, Nat. Plants 2019, 5, 225.

[19] a) E. R. Monteith, P. Mampuys, L. Summerton, J. H. Clark, B. U. W. Maes, C. R. McElroy, Green Chem. 2020, 22, 123; b) C. R. McElroy, A. Constantinou, L. C. Jones, L. Summerton J. H. Clark, Green Chem. 2015, 17, 3111.

[20] For examples of retro Friedel-Crafts reactions of alkylphenols, see: a) Y. Liao, R. Y. Zhong, E. Makshina, M. d'Halluin, Y. van Limbergen, D. Verboekend, B. F. Sels, ACS Catal. 2018, 8, 7861; b) X. Huang, J. M. Ludenhoff, M. Dirks, X. Ouyang, M. D. Boot, E. J. M. Hensen, ACS Catal. 2018, 8, 11184; c) Y. Liao, M. d'Halluin, E. Makshina, D. Verboekend, B. F. Sels, Appl. Catal. $B$ 2018, 234, 117; d) J. Zhang, L. Lombardo, G. Gözaydın, P. J. Dyson, N. Yan, Chin. J. Catal. 2018, 39, 1445; e) D. Verboekend, Y. Liao, W. Schutyser, B. F. Sels, Green Chem. 2016, 18, 297; f) T. Sato, T. Adschiri, K. Arai, J. Anal. Appl. Pyrolysis 2003, 70, 735 g) T. Sato, G. Sekiguchi, M. Saisu, M. Watanabe, T. Adschiri, K. Arai, Ind. Eng. Chem. Res. 2002, 41, 3124; h) G. A. Olah, G. K. S. Prakash, P. S. Iyer, M. Tashiro, T. Yamato, J. Org. Chem. 1987, 52, 1881; i) P. Schneider, M. Kraus, V. Bažant, Collect. Czech.
Chem. Commun. 1962, 27, 9; j) P. Schneider, M. Kraus, V. Bažant, Collect. Czech. Chem. Commun. 1961, 26, 1636.

[21] Next to dealkylation of phenolics, also deacylation has been reported, see: a) T. Patra, S. Manna, D. Maiti, Angew. Chem. Int. Ed. 2011, 50, 12140; Angew. Chem. 2011, 123, 12344; b) A. Modak, A. Deb, T. Patra, S. Rana, S. Maity, D. Maiti, Chem. Commun. 2012, 48, 4253.

[22] "Acetaldehyde": M. Eckert, G. Fleischmann, R. Jira, H. M. Bolt, K. Golka, Ullmann's Encyclopedia of Industrial Chemistry, Wiley-VCH, Weinheim, 2006.

[23] a) G. A. Olah, T. Mathew, A. Goeppert, G. Rasul, G. K. Prakash, P. M. Esteves, J. Am. Soc. Mass Spectrom. 2004, 15, 959; b) G. A. Olah, T. Mathew, E. R. Marinez, P. M. Esteves, M. Etzkorn, G. Rasul, G. K. S. Prakash, J. Am. Chem. Soc. 2001, 123, 11556.

[24] J. Buendia, J. Mottweiler, C. Bolm, Chem. Eur. J. 2011, 17, 13877.

[25] a) C. W. Lahive, P. J. Deuss, C. S. Lancefield, Z. Sun, D. B. Cordes, C. M. Young, F. Tran, A. M. Slawin, J. G. de Vries, P. C. Kamer, N. J. Westwood, K. Barta, J. Am. Chem. Soc. 2016, 138, 8900 ; b) M. Scott, P. J. Deuss, J. G. de Vries, M. H. G. Prechtl, K. Barta, Catal. Sci. Technol. 2016, 6, 1882; c) P. J. Deuss, M. Scott, F. Tran, N. J. Westwood, J. G. de Vries, K. Barta, J. Am. Chem. Soc. 2015, 137, 7456; d) A. Kaiho, M. Kogo, R. Sakai, K. Saito, T. Watanabe, Green Chem. 2015, 17, 2780; e) M. R. Sturgeon, S. Kim, K. Lawrence, R. S. Paton, S. C. Chmely, M. Nimlos, T. D. Foust, G. T. Beckham, ACS Sustain. Chem. Eng. 2014, 2, 472; f) S. Jia, B. J. Cox, X. Guo, Z. C. Zhang, J. G. Ekerdt, ChemSusChem 2010, 3, 1078; g) U. Westermark, B. Samuelsson, K. Lundquist, Res. Chem. Intermed. 1995, 21, 343.

[26] a) J. M. Kremsner, C. O. Kappe, Eur. J. Org. Chem. 2005, 3672; b) N. Akiya, P. E. Savage, Chem. Rev. 2002, 102, 2725. 